\title{
Qualitative Health Research
}

http://qhr.sagepub.com

\section{Shifting the Focus: Sequential Methods of Analysis With Qualitative Data}

Lucy Simons, Judith Lathlean and Corinne Squire

Qual Health Res 2008; 18; 120

DOI: $10.1177 / 1049732307310264$

The online version of this article can be found at:

http://qhr.sagepub.com/cgi/content/abstract/18/1/120

\author{
Published by: \\ (5)SAGE Publications \\ http://www.sagepublications.com
}

Additional services and information for Qualitative Health Research can be found at:

Email Alerts: http://qhr.sagepub.com/cgi/alerts

Subscriptions: http://qhr.sagepub.com/subscriptions

Reprints: http://www.sagepub.com/journalsReprints.nav

Permissions: http://www.sagepub.com/journalsPermissions.nav

Citations (this article cites 19 articles hosted on the

SAGE Journals Online and HighWire Press platforms):

http://qhr.sagepub.com/cgi/content/refs/18/1/120 

Analysis With Qualitative Data

\author{
Lucy Simons \\ Judith Lathlean \\ University of Southampton, Southampton, UK \\ Corinne Squire \\ University of East London, London, UK
}

\begin{abstract}
The purpose of this article is to illustrate both the processes of data analysis and the methodological development involved in adopting the sequential use of two data analysis methods applied to the same data set. Understanding of the phenomena of interest was sought through examining both the content and the form of nurses' accounts of practice experiences. Initially, a method of thematic content analysis was applied to understand what the nurses said about their experiences. The core theme of nurses' change agency derived from this analysis was examined further through a method of narrative analysis. In the second analysis, the focus was shifted to how the nurses accounted for their experiences. The innovative use of iterative, sequential methods of analysis revealed greater complexity and depth of understanding of the phenomena than would have been achieved with one method alone.
\end{abstract}

Keywords: qualitative data analysis; thematic analysis; narrative analysis

$\mathrm{T}$ he very essence of qualitative research is the rich and detailed insights that can be afforded by the indepth examination of a phenomenon. The data generated with qualitative methods are often voluminous, and researchers are faced with the tricky task of narrowing down their inquiry to avoid the resulting analysis being little more than an extensive list of instances and observations (Silverman, 2000). This part of the research process can be deeply uncomfortable, as choices about the direction to take are made and other avenues are left unexplored (Doucet \& Mauthner, 1998). These contingent processes are not readily reported in the written reconstructions of research reports, in part because of academic conventions requiring clean retrospective reporting. Furthermore, it has been argued that literature on conducting qualitative research primarily focuses on data generation and much less on the procedures for analyzing the data (Polkinghorne, 1995). Researchers

\footnotetext{
Authors' Note: All of the community mental health nurses who participated in the study are warmly thanked for their willing involvement, as is Professor Tony Kendrick for academic supervision in the conduct of this research. Correspondence concerning this article should be addressed to Lucy Simons, Senior Research Fellow, School of Nursing and Midwifery, Nightingale Building, University of Southampton, Highfield, Southampton, SO17 1BJ, United Kingdom; e-mail: 1.simons@soton.ac.uk.
}

are often searching for an "instruction book" on how to apply particular methods, and complaints have been made about the lack of clear guidance for using particular analytic approaches (McCance, McKenna, \& Boore, 2001). In part, this lack comes about because of the inherently intuitive process of researchers working intimately with their data and the difficulties in articulating this to others. Another reason for this difficulty is that methods developed for one arena of work often cannot be easily applied to another. Even within health research, qualitative approaches developed in studies of particular conditions and populations often translate with difficulty to different circumstances.

These problems of articulating analytical processes are compounded in studies in which more than one approach has been used. In this article, we report on one such study in which two analytical methods were adopted - first, because of the nature of the data generated and, second, because of a concern that one method alone was insufficient to uncover the full meaning of the data. We aim to illustrate both the processes of data analysis and the methodological development involved in adopting the sequential use of two data analysis methods applied to the same data set. In doing so, instead of focusing on either the gritty reality of the participants' accounts or the way in which these realities 
were constructed (Silverman, 2000), the analysis was an attempt to examine both and thus to extend the understandings that would be derived from one method alone.

To pursue this aim, the topic of the research is first introduced and the study briefly described. The process of the data analysis is then presented in detail, with insights into the findings, as appropriate, to demonstrate the value of the methods chosen. Finally, there is a discussion of the issues raised by taking a sequential approach to applying more than one method in the analysis of qualitative data. As the purpose of this article is primarily to offer a methodological discussion, there is limited scope for detailed consideration of the findings and suggested implications.

\section{The Research}

This research study was part of a larger project that aimed to answer a clinical question: Are community mental health nurses (CMHNs) effective in treating people with common mental health problems in primary care? This issue had been taxing policy makers in the United Kingdom during the mid to late 1990s. Although it was evident that general practitioners (GPs) wanted to refer people with common mental disorders to specialist CMHNs for support and treatment (Badger \& Nolan, 1999; Double, 1999), policy makers felt these specialist services should be reserved for those people with severe and enduring mental health problems (Butterworth, 1994). A randomized controlled trial was commissioned by the U.K. Department of Health to answer this question in clinical terms; that is, to find out whether CMHNs were more cost-effective in treating people with common mental health problems than were GPs, who were the usual source of care at the time (Kendrick et al., 2006). In addition to assessing the cost-effectiveness of different treatment interventions, this trial provided the opportunity to understand the nurses' experiences of treating people with common mental health problems in the context of the trial and to ascertain whether they would want the treatment of people with common mental disorders as part of their routine, everyday practice. Most research prior to this had sought GPs' and other practitioners' views of the CMHN role and function (Badger \& Nolan, 1999; Crawford, Carr, Knight, Chambers, \& Nolan, 2001; Double, 1999; Hannigan, Stafford, \& Laugharne, 1997), with little investigation of the CMHNs' own views of their role. Therefore, understanding the nurses' perspectives was considered very important to aid the policy recommendations stemming from the trial results. For example, if the trial found that
CMHNs were more effective in treating people with common mental health problems, it would be difficult to implement such a policy if the nurses were resistant to working with this client group.

It is this study of nurse perspectives, conducted alongside the trial, that is the focus of this article. We adopted an instrumental case study approach (Stake, 2001), guided by the main principles of case study as outlined by Yin $(1994,2003)$; that is, it was a study of phenomena in their everyday context, with unclear boundaries between the phenomena and context, and multiple sources of evidence were used. Although the trial context was not a normal practice environment for the CMHNs, the aim was to examine and expose the nurses' experiences as normally as possible within the trial, rather than placing any further controls or conditions on them. The study was designed in two distinct but interrelated phases, drawing on different sources of evidence to answer two primary research questions. First, the study was designed to provide an understanding of the experiences of CMHNs treating people with common mental health problems in the context of a treatment trial (Part 1). Second, it was designed to explore CMHNs' views concerning the nature of common mental health problems and their role in treatment (Part 2). The methods adopted in Part 1 of the study and the issues emerging from the chosen approaches are the focus of this discussion. Part 2 of the study has been reported separately (Simons, Lathlean, \& Kendrick, 2006).

\section{Sampling the CMHN Participants}

In the trial, the participating CMHNs were allocated to one of two treatment groups. Some had been specially trained in a psychological approach, problem-solving treatment, and were asked to offer only this to patients referred to them throughout the trial. This type of brief, highly structured intervention, derived from cognitive behavioral therapy (CBT), has been found to be effective in the treatment of depression in primary care (Mynors-Wallis, Gath, Day, \& Baker, 2000). CBT approaches are recommended as the psychological treatment of choice for many mental disorders such as anxiety, depression, obsessive-compulsive disorder, schizophrenia, and some eating disorders (e.g., National Institute for Health and Clinical Excellence, 2007). The training and supervision of these nurses was organized specifically for the trial. It consisted of 3.5 days of training with supervised practice with five patients prior to the trial and fortnightly group supervision available throughout the trial (for more detail, see 
Kendrick et al., 2005). The nurses in the other treatment group were asked to employ the skills they normally used to help patients get better as quickly as possible (hereafter referred to as the generic approach). All nurses in this group were offered training in problem solving at the end of the trial.

A total of 24 CMHNs took part in an individual detailed interview about their experiences of practicing in the context of the trial. Of these, 12 had been allocated to the problem-solving treatment group and 12 to the generic group.

\section{Method of Data Generation}

The interviews with the nurses were guided by the principles of the Active Interview (Holstein \& Gubrium, 1995). With this approach to interviewing, the passive respondent is rejected in favor of an active participant whose ideas are continually assembled during the interview process. The interview process is not about retrieving knowledge from a respondent but promoting a participant to construct knowledge (Kvale, 1996). Similarly, the interviewer is not viewed as an excavator of knowledge but a constructive agent who influences the interview outcomes (Fontana, 2002). With this approach, the skill of the interviewer is not to "facilitate the candid expression of opinions and sentiments" (Holstein \& Gubrium, 1997, p. 120) but to stimulate the participants' interpretative capabilities. The interviews opened with asking the nurses to describe the people they had encountered for the trial and how they had gone about treating them. Probing for elaboration and clarification was used, when appropriate, to gain detailed accounts. As the interview progressed, alternative situations or interpretations were offered to the nurses to prompt discussion and reflection. In this way, the interviews were designed to move beyond a description of events or experiences and became a co-constructed product allowing consideration of both the whats (content) and the hows (form) of the interview-generated conversations (Holstein \& Gubrium, 1995).

This appeal to attend to both the content and the form of language in the interviews prompted consideration of how to carry such attention through to the analysis. First, an expressivist-constructivist theory of language (Schwandt, 2002) was adopted to underpin both foci of attention in the interpretation of the nurses' accounts. This approach to language rejects the notion that social researchers can collect the facts of people's lives when engaging them in conversation. Drawing on the critique of the standardized interview (Holstein \& Gubrium, 1997), this theory holds that the social processes of conversation are as much a part of the information exchange as the content of the ideas expressed. Adopting this theory requires taking a critical stance to language by not taking at face value what people say and by examining how people construct their talk. In expressivist-constructivist theory, language is viewed as a medium for expressing concepts and experience while at the same time attending to the construction of the accounts during the expression of ideas. Language is not viewed as simply (a) a tool for gaining knowledge of the world in an objective process (Schwandt, 2002), (b) a transparent medium for the transmission of ideas (Silverman, 1993), or (c) a mirror reflecting the reality of people's lives (Burr, 1995). The analytic approaches eventually settled on for this study were aimed to offer an interpretation that addressed the expressivist-constructivist theory of language on two levels: the content of the talk and the form of the language used to convey the content. The theory fits with the principles of the Active Interview (Holstein \& Gubrium, 1997) and allowed for consideration of the whats and the hows of the participants' accounts.

The Active Interview approach encouraged the nurses to account for their experiences in narrative form. In the interviews, they described particular cases and the associated treatment processes typified by temporal ordering and sequence, taken as the essential characteristics of narrative (Riessman, 2002a). It is also likely that this form of case presentation would be familiar to the nurses through their everyday work, given that individuals' narrative styles draw on the representational repertoires with which they are surrounded (Plummer, 2001). These episodic narratives occurred (spontaneously or when prompted) throughout the interviews to describe both exceptional (Labov, 1972) and habitual events (Bennet, 1986; Riessman, 2002b). The narrative form that the nurses used to relay their experiences in the trial suggested that methods of narrative analysis would be appropriate for paying attention to the form of language. This approach to health research has become increasingly popular (e.g., Greenhalgh, 1999; Mishler, 1986; Riessman, 1993), but even more than content-orientated qualitative methods, it tends to be complex and difficult to replicate. Moreover, the progress from working with content to working with the narrative form of segments data is rarely explicated, even though this progress is frequently made within narrative health research.

The content of the nurses' accounts was explored through a method of qualitative thematic content analysis. This method was applied to the whole data set. Nevertheless, from the richness of the interviews as 
experienced during fieldwork, it was apparent that this form of analysis was capturing only one part of the nurses' experiences. Methods of narrative analysis were therefore explored to add to and take further the findings from the thematic content analysis. Decisions about the exact form and process of the analysis of the narrative accounts were deferred until the thematic content analysis was complete. In this way, the two methods of data analysis were applied in a sequential manner to the same data set, with the early findings being instrumental in the direction of the later round of analysis.

\section{Analysis}

\section{Method of Thematic Content Analysis}

It was the manifest content of the data that was of interest with the first process of analysis (Kvale, 1996), and the label thematic content analysis was chosen to reflect the search for themes across the data set on the basis of the content (as opposed to form). Prefacing content with thematic also served to distinguish this method from other types of content analysis that typically focus on counting frequencies of words or other utterances (Hsieh \& Shannon, 2005; Miles \& Huberman, 1994). The complete data set was included in this analysis (i.e., the entire transcripts of all 24 interviews). The primary purpose of the analysis was to understand the nurses' experiences of treating people with common mental health problems in the context of the treatment trial. The analysis followed a standard procedure for conducting such qualitative analysis (Coffey \& Atkinson, 1996), consisting of two key stages before moving on to synthesizing the data with wider theory and literature.

Identifying categories and applying them to the data. The interview transcripts were read carefully to identify emerging codes and categories. This involved a process of breaking the text down to small units and organizing according to category, thus creating a large mass of data segments and annotations (McLeod, 2001). It is acknowledged that the categories identified did not stem just from the data but were influenced by the literature and background reading, the researchers' experience and values, and the nurses' professional culture and local practices (Ryan \& Bernard, 2000). Although it is recognized that these factors contribute to the conceptualizing process, care was taken to ensure that the categories reflected the data and that the categories fit the data rather than forcing the data to fit in with the categories.
Refining the categories into broader themes. Comparing and contrasting techniques (Tesch, 1990) were used to establish category boundaries, systematically assign data segments to categories, summarize the content of each category, and search for negative evidence. The purpose of this was to detect conceptual similarities, to refine the differences between categories, and to discover patterns. This process led to the establishment of the broader themes from the data and was a continuation of the bottom-up process in which the broader themes fit the categories. This resulted in a composite account of the nurses' experiences, drawing on the strong and recurrent themes found across categories.

\section{Findings from the thematic content analysis}

This process identified the nurses' goals in the treatment encounters. These were related to bringing about positive change for the patients and the factors that the nurses identified that facilitated or inhibited the achievement of these goals. It was apparent that the nurses ultimately wanted to be agents of this change, that is, for their actions to be instrumental in bringing about change for the patients:

I do remember one woman who did stick with things and do things, and she got better, and I discharged her and that was great. You know, you felt like, ooh, something positive has happened today. ... It made me feel I had hit the right mark with one person. (generic CMHN)

It's a bit of an ego boost, you felt that you had actually been positive, you have done something. Especially when there were no drugs involved. (generic CMHN)

A number of factors were identified that nurses described as either enhancing or inhibiting their ability to bring about change. Some of these factors related to the particular treatment approach the nurses were able to take, depending on the group of the trial to which they had been allocated. Those nurses in the generic group were, they thought, able to aim for change by using their existing skills and experience to adopt a treatment approach that was suited to the particular patient and his or her circumstances. These nurses placed importance on the ability to be responsive to the patient, on adapting to suit the patients, and on making choices about how to proceed with the encounter:

[Patients] gave me information about themselves and the difficulties that they'd encountered and, having 
sort of identified what they saw as the problem, and how I felt I might be able to work with them to get some resolution to those difficulties, I set up the treatment plan which I felt was the most beneficial to them. Something they would feel comfortable working with. (generic CMHN)

In contrast, the nurses in the problem-solving group had been asked to treat patients using this particular treatment approach only and therefore had the additional goal of "sticking to it." In some cases, the problem-solving approach was also viewed positively by some nurses as suited to their particular patients and their problems or as helping to structure the nurses' own practice:

It's been helpful to me in terms of setting objectives and looking at specific problems and not getting kind of lost in all the nebulous stuff that sometimes goes with people's lives. (problem-solving CMHN)

However, in other cases the nurses found the approach difficult to "stick" to. The nurses reported that they had difficulties with this structured approach for some patients and for some particular types of problems. In some of these cases, the nurses felt that their goal of achieving change could be compromised by the requirement to "stick to it." They felt they were unlikely to be able to do their best for patients with this approach, which did not allow them to respond flexibly on the basis of their broader expertise:

As a CMHN you're always looking at lots of different angles. Even if you go down one road, you are always looking down the other roads on the way, and you might nip into a few of them. But you can't do that with problem-solving, you know, it's very clear cut. This is what you do. And so that was where I struggled, not going down those roads. (problemsolving $\mathrm{CMHN}$ )

All nurses in the study, those in the problem-solving and the generic groups, reported experiencing nursepatient encounters in which they perceived change had been achieved and those in which no change had resulted by the end of the encounter.

Positive change agency was a strong, recurrent theme throughout the nurses' accounts of their practice, not only within the trial but also outside it, within their everyday practice. Despite the different patient groups, the nurses in the trial retained the goal of working toward the achievement of change. These findings in themselves were unsurprising - the nurses were aiming to do what most health professionals aim to do; that is, support patients to make positive change, to help people get better. Furthermore, they described the process as more rewarding when they felt that they had played an active and important role in the change process. This finding had strong resonance with both mental health nursing and brief psychological therapies. Although, as discussed previously in this article, the designated role of mental health nurses is often contested; for many, the essence of mental health nursing is the use of therapeutic relationships to bring about change for people with mental distress. For example, Altschul, a respected figure in modern mental health nursing, described how nurses should use these relationships to move forward patients' recovery (Norman \& Ryrie, 2004). Likewise, a key goal in brief psychological treatments, including problem solving, is to initiate and encourage change (Dryden \& Feltham, 1992). Because of this close resonance with the conceptual ideas of these practice areas, the finding that nurses aimed to be agents of change was designated as the core theme from the thematic content analysis.

The problem solving condition promoted CMHNs' change agency through the structural emphasis, although this also downgraded it at other times because of overstructuring, reportedly for both patient and nurse. The generic condition promoted change agency through allowing flexibility, though at times this was not sufficient to produce perceived success, for example, when the patient was perceived as unready for change.

But these findings alone did not satisfy as an adequate explanation of the nurses' experiences. For the researcher who had observed the nurses in their preparation for the trial, supported them throughout the conduct of the trial, and subsequently co-constructed their accounts of the trial experience, it felt as though something was missing. This intimate knowledge and longstanding relationship with the nurses through their time with the trial suggested that particular nurses had experienced practicing within the trial in different ways, which were not adequately reflected in the findings emerging from the thematic content analysis. This across-case analysis moved the attention away from the sense of the individual nurses, suggesting that a process of looking within each case was required (Ayres, Kavanaugh, \& Knafl, 2003). In focusing on what the nurses said about their practice in the context of the trial setting, a range of experiences was found, 
but this type of analysis appeared to gloss over how, as individuals, they accounted for their experiences (Holstein \& Gubrium, 1995). Trying to unpick this "how" was the driver for applying the second method of analysis to the data.

\section{Analysis of Narratives}

As indicated previously, once the narrative form of the parts of the interview texts had been revealed, the intention was to explore methods of narrative analysis. The particular approach taken was directly influenced by the findings from the thematic content analysis. As the conclusion from the analysis of content was that nurses aimed to be agents of change, an examination of the narrative accounts of the treatment encounters gave the opportunity to test out whether representations of agency were also apparent in the nurses' construction of their accounts.

After a thorough exploration of a range of methods of narrative analysis, an approach developed by Riessman (2002a) was adopted. With micro analysis of the text, this approach is aimed at understanding how narrators construct their social position in the stories they tell. Drawing on Goffman's (1959) conceptualization of "face" and Langellier's (1989) notion of performative narratives, Riessman argued that the narrator performs a preferred identity during a social interaction (e.g., in an interview), and the identity accomplished is situated in that particular social interaction. This approach allows the analyst to consider the social positioning of the narrator, that is, how the narrator chooses to position himself or herself in relation to the audience, characters, and events. Riessman identified two main social positions: agentic (i.e., demonstrating agency) and passive. This approach struck a chord with the aims for the second phase of analysis: (a) the approach explicitly focused on the constructing of elements of the narrative accounts; (b) the approach revealed something about the individual narrators of the stories, which was the element missing in the composite, content-based account; and (c) the concept of agency, which had emerged strongly from the thematic content analysis, was examined further within the structure and sequencing of material. The narrative analysis was specifically focused on clearly identifiable nurse-patient encounter stories. These were narratives of episodes of treatment, again paralleling Riessman's approach, that occurred in one form or another, in varying frequency, in almost every interview. These were the clearest forms of representation, in which agency and passivity could be identified within narrative language, relatively independently of other forms of talk such as description, theory, or argument.

In analyzing these encounter narratives, representations of agency were equated with representations of the nurses' goal-directed determination to achieve the aims of the treatment encounter, that is, to bring about change for the patient. The construction of agency in the narrative accounts was identified in circumstances in which the nurse narrators assumed control over the events of the narrative, when they acted purposefully to initiate action, and when their actions were presented as instrumental to the outcome of the treatment encounter. This narrow definition of agency is more akin to the idea of intentional action (Burks, 2001), or working on positioning within narrative (Phoenix, in press), than to an idealized concept of agency in which the actor is unconstrained by anything other than the natural environment (Bohman, 1999). However, this relatively narrow interpretation of agency fits with the limited scope available to the nurses, to exercise agency within the controlled trial setting.

The approach to language also recognized that people do not simply "make things up" as they go along, without any prior knowledge of how to assemble such accounts. There is a socially and culturally relevant stock of resources on which people draw to construct their accounts. These have been referred to as "interpretative resources at hand" (Holstein \& Gubrium, 1995), a "frame of explanation" (Silverman, 1993), and "linguistic devices" (Riessman, 1993). One of the guiding principles of the interview approach had been to activate the participants' interpretative capabilities, and therefore, the analysis should also take account of these interpretative resources. Because the nurses had been taking one of two treatment approaches for the trial, it was likely there would be a distinction between the interpretative resources drawn on by nurses in the two groups. When assembling their accounts of their trial experiences, the nurses in the problem-solving group would, for example, be likely to use the language specific to the particular model in which they had been trained. Their construction of agency might focus around the implementation of this model, whereas in the generic group agency might be characterized by an account of assessing the patient's problems and then choosing the treatment approach deemed most appropriate, reflecting the nurses' experiences of providing a responsive and flexible treatment. The language associated with the nurses' condition-specific, everyday practice might thus be drawn on to provide appropriate frameworks for narration, 
although they were probably not the only language resources used.

The method of analysis involved examining the actions that took place in each narrative, how these actions were attributed to the characters in the story, and the way in which the narrator used language in the account to frame these actions. As the thematic content analysis had found the nurses' primary aim was to be agents of change, whether they would construct their accounts of the treatment encounter to position themselves with agency was of interest. Indicators of such agentic positioning would include, for example, a framing of their own actions as voluntary or instrumental. If this was found in the narratives of change, then it would also be of interest to know how the nurses constructed their social positioning in the narratives of treatment encounters that did not result in change. If their aim to be an agent of change was compromised, would this affect the way they constructed their position in the narrative of the "unsuccessful" treatment encounter? In these cases, instead of being defined by purposeful and instrumental actions, the construction of the nurses' position might work against the agentic position. Here, narrators may construct a passive account by giving power over to other people or factors in the narrative and presenting the central characters as victims of a particular circumstance, reacting to the events around them rather than acting purposefully (Riessman, 2002a).

To specifically look at the construction of agency, or its absence, by active or passive selfpositioning in relation to the nurses' perception of the occurrence of change, particular narratives were chosen from the corpus of case narratives. It was those narratives about nurse-patient encounters in the context of the trial in which the primary or organizing plot idea was either the achievement of change or the failure to achieve change, which were of primary interest. Selecting these narratives from the corpus yielded 69 narratives, with at least 1 from 22 participants (11 from each trial group). The narratives of the other 2 participants were of a general nature rather than specific narratives about individual nurse-patient encounters in the context of the trial.

Although it was anticipated that the social positioning constructed by the nurses might depend on the outcome of the encounter, it has also been argued that narrators might shift between the agentic and passive positions at different points of a narrative or across different stories (Riessman, 2002a). In this study, given the nature of psychological treatments that progress through a number of sessions across the whole treatment encounter, it was highly probable that the social positioning might alter as the narrative reflected the progression of the treatment encounter. In the analysis, we therefore sought to identify patterns in social positioning within and between each nurse's narratives, between the two trial groups, and across the sample of narratives as a whole. Each narrative was read through this lens, with a systematic record kept of the narrator's occupation of active and passive social positions.

\section{Findings From the Analysis of Narratives}

This micro analysis of the narrative accounts of treatment encounters revealed that although agentic positions were apparent in some narratives, they were not universally present across all the narratives or all the nurse participants. In many of the narratives examined, the nurses constructed passive positions or shifted between agentic and passive positions. It was also apparent that the social position constructed was not necessarily related to what appeared, from the thematic content analysis, to be the most salient outcome of the treatment encounter, that is, whether change was perceived to have occurred or not.

Agentic positioning was characterized by the nurses portraying themselves in active roles in the narratives and driving forward the events of the encounter. In the problem-solving group, these nurses were actively applying the problem-solving technique, whereas in the generic group the nurses were making assessments and decisions about the preferred treatment approach for that encounter. This positioning was achieved by nurses in some encounters in which change was not considered to have happened for the patient and in many encounters in which change did happen. This is illustrated in Narrative Excerpt 1. Throughout the narrative, the nurse maintained an agentic position, making treatment decisions (lines 85 to 88 ) and being purposeful in her treatment approach (lines 91 and 284 to 291) despite the lack of engagement from the patient. The construction of the narrative thus suggests something quite different about the nurse's positioning than a content analysis of the nurse-patient encounter would indicate. 
Narrative Excerpt $1^{1}$

Narrative From a Generic CMHN Demonstrating an Agentic Social Position

CMHN: $\quad$ Um I only had one person $\quad 84$ um who in fact who I didn't do any 85 relaxation with I didn't think he 86 needed it but he wasn't I would say but $\quad 87$ he wasn't particularly committed 88 I didn't feel to working um (4) I can't 89 remember if I didn't, um may be I 90 I'm sure I gave him things to do but he 91 didn't do it, and he was one 92 person I would say nothing changed with 93 him anyway I didn't THINK he 94 was motivated right at the beginning (3) 95 I think he was more a bit of low 96 mood rather than anxious. $\quad 97$

R: $\quad$ And then and then there $\quad 254$

was the guy you said? 255

CMHN: First man I saw client. I would say 256 um had very little motivation $\quad 257$ um (3) has felt low before if I recall it's 258 going back some time now. 259 R: Yeah that would be quite $\quad 260$ CMHN: Had been in prison. Had been in 261 prison yeah (2) I FELT AGAIN 262 that this was probably quite a lot easier. Only 263 one I felt there was 264 quite a lot of personality issues there and um $\quad 265$ (5) very reluctant I mean 266 said all the right things but didn't actually do $\quad 267$ any anything that he'd 268 said he'd do. $\quad 269$

R: Right huh huh (6) 270

CMHN: I think it well I did feel a bit 271 frustrated with him because I think 272 may be he was my first one and I felt oh 273 god you know very little effort 274 going in here um almost like um (3) knowing $\quad 275$ that not a lot will change 276

R: Right huh huh $\quad 277$ CMHN: Yeah 278

R: So you said he had little motivation, $\quad 279$ what was it that er led you to $\quad 280$ think that? 281

CMHN: Because he he didn't do any of the 282 things he was going to 283 you know like keeping a diary or you know $\quad 284$ in in what was it increasing 285 things that he used to do that he used to like $\quad 286$ doing, no none of that, 287 none of the gym none of the you know 288 especially when you can get that er 289
GP erm you know referrals to the gym he 290 probably he didn't even have to 291 pay::: for it all you do is just turn up um 292 but (2) yeah but there you 293 are yeah probably I was a bit frustrated 294

In opposition to the agentic position, the passive social positioning constructed by the nurses was characterized by the events of the encounter being presented as happening alongside the nurses' contact with the patient but without a clear indication that the nurse had been actively involved in any change achieved. This is illustrated in Narrative Excerpt 2. Here, the patient is the most dominant character in that all the actions that take place are attributed to him. In contrast, the nurse did not attribute any actions to himself during the narrative. Instead, he described how he felt about the encounter, stating that it was "rewarding" (lines 105 and 106), which he found "quite encouraging" (line 131) and "extremely good" (line 515). It was not clear what action he had actually taken during this encounter, and the fact that the problems were resolved (lines 111 to $112,117,123$ to $124)$ is described without any clear indication of who or what was responsible for this outcome.

Narrative Excerpt 2

Narrative From a Problem-Solving CMHN Demonstrating Passive Social Positioning

CMHN: But I think actually one of the most $\quad 105$ rewarding ones was 106 the e:r (.) um was a relatively young guy (.) 107 who worked in a local bank who um (1) lived 108 I think with his sister so a single guy 109 um (.) and um 110 who actually not only told me that his $\quad 111$ problems were resolved by the end $\quad 112$ but actually said you know how how he $\quad 113$ now understood about tackling his $\quad 114$ future problems you know in view of you $\quad 115$ know (.) that he not only not 116 only resolved his current problems but had $\quad 117$ learnt had learnt a way of $\quad 118$ tackling (.) um how he perceives things in $\quad 119$ the future you know um which I 120 I find that (.) actually the most rewarding $\quad 121$ of all um (.) erm: you know 122 because hopefully you know not only has $\quad 123$ has it resolved during the time 124 that I saw him but he will be able to do it $\quad 125$ himself next time which is $\quad 126$ what of course was said on the on the course $\quad 127$ itself but um (.) he 128 
actually he actually came out with that

himself and when he when he did

it um you know that was quite encouraging.

$\begin{array}{ll}\text { CMHN: I I I think like } & 508 \\ \text { I said it was it was great when that guy said } & 509 \\ \text { to me you know that he got } & 510 \\ \text { something he got something (.) for himself } & 511 \\ \text { for the future he could use } & 512 \\ \text { you know and how to perceive things } & 513 \\ \text { differently if you know I think that } & 514 \\ \text { was ur extremely good. } & 515\end{array}$

This example is particularly interesting because the nurse felt it was his most successful treatment encounter, but at no point in the account did he inscribe himself into an agentic position. These data had contributed toward the core theme in the thematic content analysis of the nurses' goal being change agency because of the way he explained how rewarding this encounter was, with the resulting outcome of change. However, as with the first narrative example, the construction of the narrative suggests a different conclusion about the nurse's social position than the thematic content analysis had indicated.

In summary, the analysis of form-examining the construction of the nurses' narrative accounts of treatment encounters-revealed the complexity of nurses' experiences to a greater extent than was possible with the thematic content analysis. Through this process, the nurses could be categorized by the way in which they constructed their social positioning, drawing out the aspects of the individual nurses' experiences that appeared to be glossed over by the previous findings. It could be argued that the linguistic forms in which nurses express their trial experiences are subject to a number of interpretations. There are social rules that allow the expression of agency indirectly, precisely by eliding it - as in the second narrative example, in which the nurse's effectiveness could be said to be heavily implied if not explicitly stated. Similarly, declared agency in the first example sometimes works rhetorically to indicate agency's lack. Here, the narrator's attempts to be effective are repeatedly counterposed to factors that must override them, reducing the significance of agency. In addition, individual, social, and cultural styles of speech concerning agency vary. However, the ubiquity of change agency in the thematic content of the interviews, and the agent-directed repertoire of case reporting by health professionals - which was shared by all the nurses - means new understandings produced from the positionings within the nurse-patient encounters are persuasive.

\section{Discussion}

The approaches to analysis taken in this study were intended to make the most of the rich data generated by qualitative methods. The study was an attempt to know more about and extend understandings of the phenomena being explored by paying attention to the content and the form of the participants' accounts. The recognition of the storied nature of the data, once fieldwork was underway, prompted interest in methods of narrative analysis. This led to an expectation that deeper understandings would be reached by paying attention to the narrative segments of the interview text and the construction of these narratives. Furthermore, the belief that a single process of analysis was not sufficiently representing individual participants' experiences added to the argument that further analysis would be appropriate.

The sequential approach to methods of analysis was similar to what has been called "following a thread" (Moran-Ellis et al., 2006, p. 54). Although this phrase was coined in the context of mixed methods of data collection (quantitative, qualitative, visual, and multimedia data), it provides a useful description for the approach taken in this study. The central theme revealed in the first process of analysis was investigated further in the following analysis. In this way, the analysis was based in the first instance on a grounded inductive approach but then developed through a focused iterative process.

Using two methods of analysis in this sequential manner brought deeper understanding of this subject than would have been reached through one method alone. However, concern is often voiced in relation to the mixing of different methods, particularly about whether chosen approaches are commensurate with each other or are underpinned by incompatible ontological and epistemological assumptions. Riessman (2002a) argued that narrative analytic methods can be used in conjunction with other methods of analysis (including quantitative analysis) but that some "fancy epistemological footwork" (p. 706) is required because the interpretative perspective that underpins narrative work may be different from the realist assumptions of other forms of qualitative analysis. Similarly, Polkinghorne (1995), drawing on Bruner's (1985) categorization of modes of thought, distinguished between paradigmatic (scientific) and narrative (emotional) modes of knowing. Bruner argued that, although complementary, these modes of knowing were essentially incommensurable because of the different operating principles and procedures for verification. Polkinghorne 
applied this categorization of modes of thought to distinguish between two types of narrative inquiry: analysis of narrative and narrative analysis. Although the former draws on paradigmatic cognition and the latter on narrative cognition, Polkinghorne argued that the general principles are shared and that both types of inquiry can make important contributions to knowledge.

Although these problems vex researchers in crossparadigmatic research - that is, research using methods that draw on different theoretical assumptions (Guba \& Lincoln, 1994) - the approach taken in this study means that we did not have to contend with these issues. Both methods of data analysis were underpinned by the same theoretical position. The approaches taken in the interviews and the methods of analysis were attempts to strike a balance between the whats and hows in the generation and analysis of talk (Fontana, 2002; Holstein \& Gubrium, 1995). The underpinning theory of language offered a bridge between focusing on the expression of ideas and the contribution of constructive elements to understand language. In this way, attention can be paid to both important aspects of language, with each contributing something to the understandings derived, but one was not championed at the expense of the other. Language consists of these two elements. Using analysis, it is possible to pay attention to both without necessarily neglecting one or the other. Furthermore, according to Polkinghorne's (1995) classification, both methods of analysis adopted within this study fit within the paradigmatic mode of thought. Although focused on different aspects of the raw data, both processes involved breaking down the accounts before building a composite picture to describe and understand the nurses' experiences of practicing within the context of the trial. The thematic content analysis was a process of inductive categorization of what the nurses had said about their experiences. This started with breaking down the interview transcripts as numerous categories and codes were assigned to data segments, followed by refinement, through comparing and contrasting, to produce a composite account that identified the commonalities across the data set. Likewise, the analysis of narratives involved first deconstructing the nurses' narratives to categorize the narrative segments according to how the participant had constructed his or her social position, followed by a search for common patterns across the narrative corpus. Unlike using mixed methods, this study did not involve viewing a phenomenon from different standpoints underpinned by different theoretical assumptions. Rather, it was about shifting the focus-viewing the same object from the same standpoint but adjusting the lens to bring into view particular aspects of the phenomenon, one after another (Moffat, 2006).

Using more than one approach to analyze qualitative data is not new. For example, other researchers examining nurses' practices have found that more than one method can deepen the understandings of an experience (McCance, 1999), reinforce and strengthen the findings from one method (Chapman, 1986), or give a slightly different emphasis on overlapping findings (Savage, 2000). These authors concluded that the different analyses did not lead to radically different interpretations. However, in this study, by shifting the focus to examine different aspects of the text in turn, and by further exploring the core concept that emerged from the initial analysis, important new insights emerged, as demonstrated by the narrative examples above, which were divergent from the early findings.

The sequential analysis revealed that the social positioning constructed by the nurses was not related simply to the perceived outcome of the treatment encounter, as initially suggested. Rather, the social positioning was related to individual nurses in that they could be grouped into one of two types. The first was a group of nurses who constructed a position in which they assumed control over the events in all the encounters they narrated and who retained this position even if they perceived the primary aim in the treatment encounters-positive patient change-was compromised. The second type was a group of nurses who constructed predominantly passive positions in the trial encounter narratives. These two main social positions were found for nurses in both the generic and problem-solving trial groups, suggesting that there were different ways in which individual nurses conceptualized and represented their role in treatment encounters, regardless of the treatment approach or outcome. This finding has interesting implications for nursing practice. It suggests two different expressive orientations toward treatment, operating across a common conceptual concern with change agency.

There was one notable difference between the narratives of nurses in the two treatment conditions. Nurses in the problem-solving group constructed their social position more consistently throughout the narratives examined, whereas those in the generic group constructed shifting positions in some narratives or in parts of narratives. This was the most striking difference between the two treatment groups. The consistent 
social positioning found with the nurses in the problemsolving group suggested that the requirement for nurses to offer a particular treatment approach in the context of the trial, regardless of the nature of the patient's problems, resulted in a polarization of their social positioning. It could be that the unfamiliarity of the problem-solving approach produced this polarization, but the strong structuring of and emphasis on problemsolving treatment that emerged from the thematic content analysis suggest that it was the nature of the approach that generated polarized social positioning.

These findings are important to help understand the impact of controls on practitioners' behavior. Such impact may result from both a controlled trial setting and the use of highly structured psychological treatment approaches such as problem solving. The findings demonstrate how evidence generated in trial settings about the nature of treatment experiences may differ, for both practitioners and patients, from those generated in regular practice settings because control itself had significant effects on the ways in which practice was experienced. This control was further extended in the problem-solving arm because of the fixed parameters of the structured approach. The suggested impact on practitioners of highly structured treatments found in this study requires further investigation, particularly when structured approaches such as CBT are strongly recommended for many mental health problems.

The polarized positions found with the nurses in the problem-solving group may also stem from their responses to delivering a psychological intervention. Although mental health nursing and psychology are closely aligned, there is ambiguity among mental health nurses about the use of psychological concepts and approaches to treatment, which have been found to act as both empowering and disempowering mediators in mental health nurses' talk about their practice (Mac Neela, Scott, Treacy, \& Hyde, 2007). Further examination of the relationship between mental health nursing and psychology is suggested, with an exploration of the connections between the concept of agency as examined in this study and empowerment as examined by Mac Neela and colleagues (2007).

\section{Conclusion}

The innovative aspect of the analysis adopted in this study was the iterative nature of the methods, with the second analysis derived from and taking forward the findings of the first. However, because this process was developed after the data were generated, the divergence in the findings can be reconciled only at the point of interpretation (Moran-Ellis et al., 2006). Although there were differences in the nurses' construction of agency, it is possible only to speculate why, if the nurses aimed to be agents of change, they did not construct their positions with a sense of agency in all the treatment encounters examined. When findings from more than one method converge, theoretical integration and reconciliation are more straightforward, serving to reinforce and strengthen the findings. But when there is divergence, as found with this study, the explanations are limited to informed speculations.

Notwithstanding this limitation, shifting the focus from one aspect of the data to another, and following the suggested thread, led to deeper and more meaningful explanations of the phenomena under consideration. By taking the reader through this analytic journey, it is anticipated that the possibilities open to qualitative researchers, as they grapple with the contingent processes involved in analysis, were demonstrated. The analytic methods adopted are vital to reaching a greater understanding of the phenomena and better presenting the complexity of the social processes involved. Inevitably, the direction chosen in this study was one of many that were available at the start of the process. By detailing these methods, our intention is not to suggest that this is the way such analysis "must be done" (Cheek, 2004, p. 1148). Rather, as Doucet and Mauthner (1998) suggest, "What ever the losses and gains involved . . . we must document the paths, detours, and shortcuts we have chosen at each stage of the research journey" (p. 12). The scholarly journey might be at least as important as the knowledge generated.

\section{Note}

1. Transcript conventions include the following: $\mathrm{CMHN}=$ nurse participant; $\mathrm{R}=$ interviewer; $()=$. pause of less than 1 second; (3) $=$ length of pause in seconds; CAPITALS = increase in voice tone relative to previous talk; : = this follows a prolongation of the immediately prior sound (length of row of colons indicates the length of prolongation; Bailey, 2001; Potter \& Wetherell, 1994; Silverman, 1993). Line numbers indicate where in the interview the narrative segments appeared.

\section{References}

Ayres, L., Kavanaugh, K., \& Knafl, K. A. (2003). Within-case and across-case approaches to qualitative data analysis. Qualitative Health Research, 13, 871-883.

Badger, F., \& Nolan, P. (1999). General practitioners' perceptions of community psychiatric nurses in primary care. Journal of Advanced Nursing, 6, 453-459. 
Bailey, P. H. (2001). Death stories: Acute exacerbations of chronic obstructive pulmonary disease. Qualitative Health Research, 11, 322-338

Bennet, G. (1986). Narrative as expository discourse. Journal of American Folklore, 99, 415-434.

Bohman, J. (1999). Practical reason and cultural constraint: Agency in Bourdieu's theory of practice. In R. Shusterman (Ed.), Bourdieu: A critical reader (pp. 127-152). Oxford, UK: Blackwell Science.

Bruner, J. (1985). Actual minds, possible words. Cambridge, MA: Harvard University Press.

Burks, K. J. (2001). Intentional action. Journal of Advanced Nursing, 34, 668-675.

Burr, V. (1995). An introduction to social constructionism. London: Routledge.

Butterworth, T. (1994). Working in partnership: A collaborative approach to care. The review of mental health nursing. Journal of Psychiatric and Mental Health Nursing, 1, 41-44.

Chapman, G. (1986). "Talk, text and discourse": Nurses' talk in a therapeutic community. Unpublished doctoral dissertation, Goldsmith's College, University of London.

Cheek, J. (2004). At the margins? Discourse analysis and qualitative research. Qualitative Health Research, 14, 1140-1150.

Coffey, A., \& Atkinson, P. (1996). Making sense of qualitative data: Complementary research strategies. Thousand Oaks, CA: Sage.

Crawford, P., Carr, J., Knight, A., Chambers, K., \& Nolan, P. (2001). The value of community mental health nurses based in primary care teams: "Switching the light on in a cellar." Journal of Psychiatric and Mental Health Nursing, 8, 213-220.

Double, D. B. (1999). What do GPs want from mental health services? Journal of Mental Health, 8, 385-389.

Doucet, A., \& Mauthner, N. (1998, January). Voice, reflexivity and relationships in qualitative data analysis. Paper presented at the Qualitative Interest Group Conference, University of Georgia, Athens. Retrieved March 14, 2003, from http://www .coe.uga.edu/quig

Dryden, W., \& Feltham, C. (1992). Brief counselling: A practical guide for beginning practitioners. Buckingham, UK: Open University Press.

Fontana, A. (2002). Postmodern trends in interviewing. In J. F. Gubrium \& J. A. Holstein (Eds.), Handbook of interview research (pp. 161-175). Thousand Oaks, CA: Sage.

Goffman, E. (1959). The preservation of self in everyday life. New York: Doubleday.

Greenhalgh, T. (1999). Narrative based medicine in an evidence based world. In T. Greenhalgh \& B. Hurwitz (Eds.), Narrative based medicine: Dialogue and discourse in clinical practice (pp. 247-264). London: BMJ.

Guba, E. G., \& Lincoln, Y. S. (1994). Competing paradigms in qualitative research. In N. K. Denzin \& Y. S. Lincoln (Eds.), Handbook of qualitative research (pp. 105-117). Thousand Oaks, CA: Sage.

Hannigan, B., Stafford, A., \& Laugharne, R. (1997). General practitioners' views of community mental health services: A survey in one London borough. Journal of Interprofessional Care, 11, 287-293.

Holstein, J. A., \& Gubrium, J. F. (1995). The active interview. Thousand Oaks, CA: Sage.

Holstein, J. A., \& Gubrium, J. F. (1997). Active interviewing. In D. Silverman (Ed.), Qualitative research: Theory, method and practice (pp. 113-129). London: Sage.
Hsieh, H., \& Shannon, S. E. (2005). Three approaches to qualitative content analysis. Qualitative Health Research, 15, 1277-1288.

Kendrick, T., Simons, L., Mynors-Wallis, L., Gray, A., Lathlean, J., Pickering, R., et al. (2005). A trial of problem-solving by community mental health nurses for anxiety, depression and life difficulties among general practice patients. The CPN-GP Study. Health Technology Assessment, 9, 1-104.

Kendrick, T., Simons, L., Mynors-Wallis, L., Gray, A., Lathlean, J., Pickering, R., et al. (2006). Cost-effectiveness of referral for generic care, or problem-solving treatment, from community mental health nurses, compared with usual general practitioner care for common mental disorders. Randomised controlled trial. British Journal of Psychiatry, 89, 50-59.

Kvale, S. (1996). InterViews: An introduction to qualitative research interviewing. Thousand Oaks, CA: Sage.

Labov, W. (1972). The transformation of experience in narrative syntax. In Language in the inner city: Studies in the Black English vernacular (pp. 354-396). Oxford, UK: Blackwell.

Langellier, K. M. (1989). Personal narratives: Perspectives on theory and research. Text and Performance Quarterly, 9, 243-276.

Mac Neela, P., Scott, A. P., Treacy, M. P., \& Hyde, A. (2007). Lost in translation, or the true text: Mental health nursing representations of psychology. Qualitative Health Research, 17, 501-509.

McCance, T. V. (1999). An exploration of the experience of caring in nursing: A hermeneutic approach. Unpublished doctoral dissertation, University of Ulster, Ireland.

McCance, T. V., McKenna, H. P., \& Boore, J. R. P. (2001). Exploring caring using narrative methodology: An analysis of the approach. Journal of Advanced Nursing, 33, 350-356.

McLeod, J. (2001). Qualitative research in counselling and psychotherapy. Thousand Oaks, CA: Sage.

Miles, M. B., \& Huberman, A. M. (1994). Qualitative data analysis: An expanded source book. Thousand Oaks, CA: Sage.

Mishler, E. G. (1986). Research interviewing. Cambridge, MA: Harvard University Press.

Moffat, J. (2006, September). The challenges and benefits of adopting two distinct but complementary approaches to analysis. Paper presented at the 6th European Qualitative Research Conference in Health and Social Care, Dorset, UK.

Moran-Ellis, J., Alexander, V. D., Cronin, A., Dickinson, M., Fielding, J., Sleney, J., et al. (2006). Triangulation and integration: Processes, claims and implications. Qualitative Research, 6, 45-59.

Mynors-Wallis, L., Gath, D., Day, A., \& Baker, F. (2000). A randomised controlled trial of problem solving treatment, antidepressant medicine and combined treatment for major depression in primary care. British Medical Journal, 320, 26-30.

National Institute for Health and Clinical Excellence. (2007). Anxiety (amended): Management of anxiety (panic disorder, with or without agoraphobia, and generalized anxiety disorder) in adults in primary, secondary and community care. Retrieved September 14, 2007, from http://guidance.nice.org .uk/CG22/niceguidance/word/English

Norman, I., \& Ryrie, I. (2004). Mental health nursing: Origins and orientations. In I. Norman \& I. Ryrie (Eds.), The art and science of mental health nursing (pp. 66-98). Buckingham, UK: Open University Press.

Phoenix, A. (in press). Analysing narrative contexts. In M. Andrews, C. Squire, \& M. Tamboukou (Eds.), Doing narrative research. London: Sage.

Plummer, K. (2001). Documents of life 2. London: Routledge. 
Polkinghorne, D. E. (1995). Narrative configuration in qualitative analysis. In J. A. Hatch \& R. Wisniewski (Eds.), Life history and narrative (pp. 5-23). London: Falmer.

Potter, J., \& Wetherell, M. (1994). Analyzing discourse. In A. Bryman \& R. G. Burgess (Eds.), Analyzing qualitative data (pp. 47-66). London: Routledge.

Riessman, C. K. (1993). Narrative analysis. Newbury Park, CA: Sage.

Riessman, C. K. (2002a). Analysis of personal narratives. In J. A. Holstein \& J. F. Gubrium (Eds.), Handbook of interview research (pp. 695-710). Thousand Oaks, CA: Sage.

Riessman, C. K. (2002b). Doing justice: Positioning the interpreter in narrative work. In W. Patterson (Ed.), Strategic narrative (pp. 193-214). Bloomington, IN: Lexington Books.

Ryan, G. W., \& Bernard, H. R. (2000). Data management and analysis methods. In N. K. Denzin \& Y. S. Lincoln (Eds.), Handbook of qualitative research (2nd ed., pp. 769-802). Thousand Oaks, CA: Sage.

Savage, J. (2000). One voice, different tunes: Issues raised by dual analysis of a segment of qualitative data. Journal of Advanced Nursing, 31, 1493-1500.

Schwandt, T. A. (2002). Three epistemological stances for qualitative inquiry: Interpretivism, hermeneutics, and social constructionism. In N. K. Denzin \& Y. S. Lincoln (Eds.), Handbook of qualitative research (pp. 189-213). Thousand Oaks, CA: Sage.

Silverman, D. (1993). Interpreting qualitative data: Methods for analysing talk, text and interaction. London: Sage.
Silverman, D. (2000). Doing qualitative research: A practical handbook. London: Sage.

Simons, L., Lathlean, J., \& Kendrick, T. (2006). Community mental health nurses' views of their role in the treatment of people with common mental disorders. Primary Care Mental Health, 4, 121-129.

Stake, R. E. (2001). Case studies. In N. K. Denzin \& Y. S. Lincoln (Eds.), Handbook of qualitative research (pp. 435-454). Thousand Oaks, CA: Sage.

Tesch, R. (1990). Qualitative research: Analysis types and software tools. London: Falmer.

Yin, R. K. (1994). Case study research: Design and methods (2nd ed.). Thousand Oaks, CA: Sage.

Yin, R. K. (2003). Case study research: Design and methods (3rd ed.). Thousand Oaks, CA: Sage.

Lucy Simons, $\mathrm{PhD}$, is senior research fellow at the School of Nursing and Midwifery, University of Southampton, Southampton, United Kingdom.

Judith Lathlean, DPhil, is professor of health research at the School of Nursing and Midwifery, University of Southampton, Southampton, United Kingdom.

Corinne Squire, $\mathrm{PhD}$, is reader in psychosocial studies and codirector of the Centre for Narrative Research, University of East London, London, United Kingdom. 